EDITOR

Roger Jones, FRCP, FRCGP

London

DEPUTY EDITOR

Alec Logan, FRCGP

Motherwell

JOURNAL MANAGER

Catharine Hull

SENIOR ASSISTANT EDITOR

Erika Niesner

ASSISTANT EDITOR

Moira Davies-Cinar

EDITORIAL ASSISTANT

Tania Marszalek

ADVERTISING EXECUTIVE

Brenda Laurent

CLASSIFIED ADVERTISING SALES EXECUTIVE Peter Wright

EDITORIAL BOARD

Richard Baker, MD, FRCGP

Leicester

Stephen Barclay, MD, FRCGP, DRCOG

Cambridge

Chris Butler, MD, MRCGP

Cardiff

Kath Checkland, PhD, MRCGP

Manchester

Mark Gabbay, MD, FRCGP

Liverpool

Clare Gerada, MBE, FRCGP, MRCPsych

London

Murray Lough, MD, FRCGP

Glasgow

David Mant, MD, FRCGP

Oxford

Tim Peters, MSc, PhD, cStat, FFPH

Bristol

Chris Salisbury, MD FRCGP

Bristol

John Sandars, MSc, MD, FRCGP, MRCP

Leeds

Mark Shapley, FRCGP, DCH, DRCOG

Newcastle-under-Lyme

Niroshan Siriwardena, MMedSci, PhD

FRCGP

Lincoln

Theo Verheij, MD, PhD, MRcGP

Utrecht, The Netherlands

Sue Wilson, BA, PhD, PGA

Birmingham

2008 impact factor: $\mathbf{2 . 2 7 8}$

EDITORIAL OFFICE

14 Princes Gate, London SW7 1PU

(Tel: 0207581 3232, Fax: 0207584 6716).

E-mail: journal@rcgp.org.uk

http://www.rcgp.org.uk/bjgp

PUBLISHED BY

The Royal College of General Practitioners,

14 Princes Gate, London SW7 1PU. Registered charity number 223106. The BJGP is published by the RCGP, but has complete editorial

independence. Opinions expressed in the BJGP should not be taken to represent the policy of

the RCGP unless this is specifically stated.

No endorsement of any advertisement is implied or intended by the RCGP.

PRINTED IN GREAT BRITAIN BY

HPM Limited, Prime House, Park 2000,

Heighington Lane Business Park,

Newton Aycliffe, Co. Durham DL5 6AR.

Printed on $100 \%$ recycled paper

\section{CHALLENGES TO ADVOCACY IN PRIMARY HEALTH CARE}

The idea that GPs should act as advocates for their patients has found its way into a number of definitions of their role over the last 30 years. The potential tension between advocacy for the individual patient and a physician's wider societal responsibilities has also been recognised. It may well be that, as first-contact primary care becomes increasingly fragmented, with a concomitant reduction in personal continuity of care and in patients' and doctors' knowledge of each other, there is less expectation of personal advocacy on either side of the relationship. In this issue of the Journal we publish a number of striking articles which highlight aspects of the advocacy role of the primary care physician in a number of settings.

This month a new system of sickness certification is being introduced in the UK, and GPs will be required to issue 'fit notes' rather than 'sick notes', which focus on a patient's ability, rather than their disability, to work. A preliminary study, ${ }^{1}$ using vignettes of sickness certification suggests that the introduction of this system will not be entirely straightforward, and Gabbay's editorial ${ }^{2}$ points out that the 'fit note' system signals a major change not only in procedure, but in doctor-patient relationships. Providing sickness certification (the cost of which exceeds that of the entire NHS) is a role that many primary care physicians do not feel adequately trained, and often feel uncomfortable, because of the conflict between acting as a patient's advocate and attempting to provide a realistic and rational assessment of ability to work. This experiment will be watched with great interest and is an important subject for future research.

Four papers deal with old age and death. Fleming and colleagues ${ }^{3}$ point out the continued problem of ensuring that old people die where they would most like to, with evidence from a large study in Cambridge, UK, indicating that many old people do not die in the place that they might have chosen. Two papers focus on long-term antidepressant prescribing in old people. A study from France shows that GPs there do not stick to prescribing guidelines, ${ }^{4}$ while a qualitative study from the UK ${ }^{5}$ explores this issue in a little more detail, suggesting that this 'off protocol' prescribing may have previously unrecognised benefits particularly, as Siriwardena points out in his editorial, ${ }^{6}$ when access to nonpharmacological therapies is poor.
An important area of advocacy is that of the management of end-of-life care and van Alfen and colleagues ${ }^{7}$ from the Netherlands have examined requests for euthanasia in general practice before and after the implementation of the Dutch Euthanasia Act. Interestingly, the Act has not been associated with an increase in the number of requests for euthanasia, which mostly come from cancer patients and are associated with increasing dependency, unbearable suffering, and depression. It may be that improvement in the standards of palliative care practice are, in part, responsible for constraining the increase in requests for euthanasia.

The central role of effective primary care as a means of securing the rights of individuals and societies to health was emphasised in the Declaration of Alma-Ata in 1978 and has been articulated more recently by the World Health Organisation in their 2008 report entitled Primary Health Care: Now More Than Ever. In their 2009 Richard Scott Lecture, ${ }^{8}$ Jan De Maeseneer and Maaike Flinkenflogel emphasise how, in the challenging context of healthcare provision in Africa, well-trained primary care teams can contribute to the achievement of the fundamental right of every citizen to have access to person-oriented high-quality primary health care.

\section{Roger Jones \\ Editor}

\section{REFERENCES}

1. Sallis A, Birkin R, Munir F. Working towards a 'fit note': an experimental vignette survey of GPs. Br J Gen Pract 2010; 60: 245-250.

2. Gabbay MB. Electronic fit notes: sickness certification in the new decade. Br J Gen Pract 2010; 60: 235-236.

3 Fleming J, Zhao J, Farquhar M, et al. Place of death for the 'oldest old': $\geq 85$-year-olds in the CC75C population-based cohort. Br J Gen Pract 2010; DOI: 10.3399/bjgp10X483959 (abridged text, in print: Br J Gen Pract 2010; 60: 275-282).

4. Lasserre A, Younès N, Blanchon T, et al. Psychotropic drug use among older people in general practice: discrepancies between opinion and practice. Br J Gen Pract 2010; DOI: 10.3399/bjgp10X483922 (abridged text, in print: $\mathrm{Br} \mathrm{J} \mathrm{Gen}$ Pract 2010; 60: 260-262).

5. Dickinson R, Knapp P, House A, et al. Long-term prescribing of antidepressants in the older population: a qualitative study. Br J Gen Pract 2010; DOI: 10.3399/bjgp10X483913 (abridged text, in print: Br J Gen Pract 2010; 60: 257-259).

6. Siriwardena N. Why do GPs prescribe psychotropic drugs when they would rather provide alternative psychological interventions? Br J Gen Pract 2010; 60(573): 241-242.

7. Van Alphen J, Donker G, Marquet R. Requests for euthansia in general practice before and after implementation of the Dutch Euthansia Act. Br J Gen Pract 2010; 60(573): 263-267.

8. De Maeseneer J, Flinkenflögel M. Primary health care in Africa: do family physicians fit in? Br J Gen Pract 2010; 60(573): 286-292.

DOI: 10.3399/bjgp10X483832

C) British Journal of General Practice 2010; 60: 233-312. 